Martínez Morales, María.

Investigadora. Universidad de Jaén. Didáctica de la Expresión Plástica y Visual.

Grupo de investigación PAI Hum 862- "Estudios en Sociedad, Artes y Gestión Cultural".

\title{
Historia de un barrio. Una acción artística como representación virtual de un lugar.
}

TIPO DE TRABAJO

Comunicación virtual.

PALABRAS CLAVE

Acción artística, lugar, comunidad, a/r/tografía.

KEY WORDS

Artistic action, place, community, a/r/tography.

\section{RESUMEN}

La comunicación que presento a continuación es una acción artística que parte de mi experiencia y que forma parte de una serie de intervenciones artísticas que desarrollo desde una perspectiva artográfica con la idea de investigar conceptos como el tiempo y lugar. Escojo la a/r/tografía como forma de indagación ya que me ofrece la posibilidad de crear nuevos discursos, conexiones e intuiciones al conectar mi práctica artística, docente e investigadora, un mapa de acciones que enriquece mi proceso creativo y la construcción de nuevas narrativas.

"Historia de un barrio", es un proyecto que investiga el barrio de Washington Heights a través de la comunidad que vive en él. Lo virtual aparece como parte del proceso creativo en la representación del concepto lugar. La acción comienza con un viaje a un lugar desconocido, a través de un recorrido no lineal de sucesos que van aconteciendo a modo de deriva. El proyecto está formado por tres partes, Cartografiando lo que no está representado, en la que voy creando una serie de representaciones visuales inspiradas en las historias de conversaciones con los vecinos del barrio y mi relación con el lugar desde una mirada autoetnográfica. La segunda parte Metáforas de papel, una forma de cuestionar la idea de lugar real/virtual a través del viaje que experimento. La tercera parte, Cuaderno de clase, una propuesta educativa basada en la deriva como metodología artística.

\section{ABSTRACT}

The proposal that I present is an artistic action that part of my experience and part of a series of artistic interventions that development from a artographic perspective with the idea of investigating concepts such as time and place. Choose the a / $r$ / tography as a form of inquiry because it offers me the possibility to create new discourses, connections and intuitions to connect my artistic practice, teaching and research, a map of actions that enriches my creative process and construction of new narratives .

"History of a neighborhood" is a project investigating Washington Heights neighborhood through community living in this place. The virtual appears as part of the creative process in the representation of the concept place. The action begins with a trip towards an unknown place through a non-linear path of events that are happening like a drift. The project is composed by three parts, the first part is called Mapping something that isn't represented, where I create a series of narratives visuals inspired by the stories of conversations with the neighbors and my connection with the place, from a autoethnographic gaze. The second part is metaphor made of paper an artistic action that it takes place in the neighborhood to questioning the idea of real / virtual place through the journey that I experiment. The third part is Class notebook, an educational proposal based on the idea of drift as artistic methodology. 


\section{CONTENIDO}

\section{INTRODUCCIÓN}

Siguiendo los pasos de una deriva, investigo a través de mi práctica artística, un recorrido irregular que parte del cuerpo como centro de percepción, una exploración del espacio indeterminado, no lineal, sin ningún orden preestablecido si no el seguido por la intuición, la emoción o la experiencia. Se trata de investigar la ciudad a través del proceso creativo donde lo importante es el camino seguido y no el lugar de llegada, caminar se convierte en un fin en sí mismo. La idea parte del concepto deriva, idea que surge en la década de los sesenta, en la Internacional Situacionista, basado en la psicogeografía, a través de la cual, el recorrido de los espacios urbanos quedan unidos a "indisolublemente al reconocimiento de efectos de naturaleza psicogeográfica, y a la afirmación de un comportamiento lúdico-constructivo, lo que la opone en todos los aspectos a las nociones clásicas de viaje y de paseo" Debord (1958). Proponen un nuevo orden ante la alineación de la vida cotidiana, desarrollan una actitud crítica proponiendo otras formas de ver la ciudad basada en nuestras vivencias, la creación de mapas como experiencia, alternativas para el surgimiento de subjetividades sociales diferentes. Escojo la idea de deriva como forma de indagación/creación ya que me permite hacer visible aquello que no está representado y como metodología artística en ámbitos educativos.

Comienzo el recorrido con la idea de representar el tiempo y el lugar desde mi estancia en Nueva York, son numerosos los artistas influyentes en esta investigación, obras, lugares e instantes que a modo de rizoma van conectando con mi obra creando un nuevo orden de posibilidades. Me interesa trabajar con el concepto de tiempo y recuperación de la memoria, recuerdos o experiencias pasadas a través distintas narrativas no lineales de acontecimientos que voy experimentando y que posibilitan la creación de nuevos significados, instantes que forman parte la investigación que parte de la idea de archivo por el interés hacia las narrativas de memoria tanto individual como colectiva.

\section{DESARROLLO}

\section{Cartografiando lo que no está representado.}

Narrativas de archivo a través de conversaciones con los vecinos.

Desde hace tiempo me interesa crear narrativas visuales y textuales para contar lo que me ocurre, en el tiempo o en algún lugar. Desde que llego a New York siento la necesidad de contar lo que voy experimentando, comienzo a acumular folletos, tickets, catálogos, entradas, trípticos, mapas, anuncios, dibujos, notas... un sin fin de registros que almaceno en esa idea de captar, de no querer olvidar instantes, los pego a modo de posit en el espejo de la cómoda como registro de instantes que de alguna forma no quiero olvidar.

Hago referencia a la obra Silence de On Kawara en el Museo Guggenheim. Una reflexión del concepto tiempo desde lo cotidiano, que parte de lo existencial como la serie "I get up" donde el artista registra la hora y lugar a través del envío de postales durante un tiempo con la hora en la que se levanta cada día, una forma de ir registrando el paso del tiempo como proceso vital y como proceso creativo.
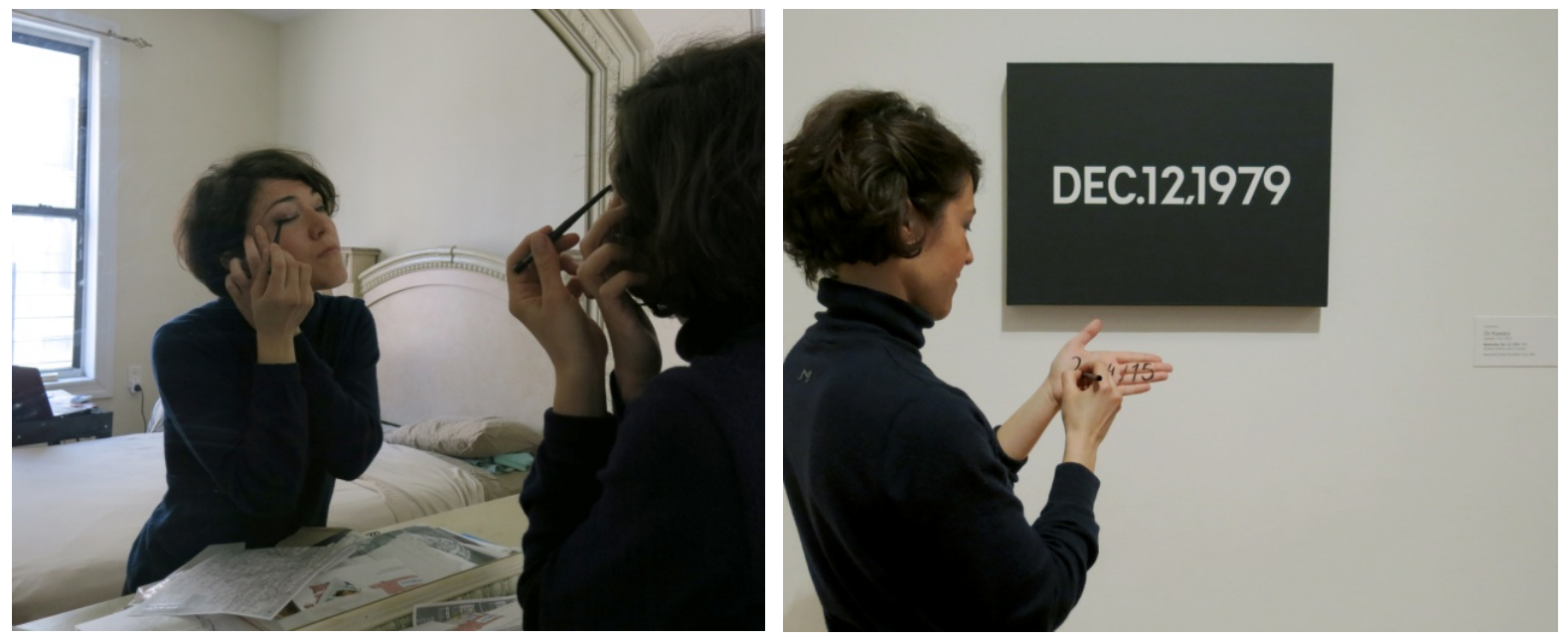

Fotoensayo Sin título, 2015, organizado a partir de dos fotografías de la autora y una cita visual indirecta On Kawara, 1979. 
El tiempo queda registrado en acciones cotidianas que realizo de forma sistemática cada día, como ir en metro al centro de la ciudad, comprar el pan o tomar el café en el bar de enfrente, tickets que guardo, registros de los distintos caminos que experimento por la ciudad.

Desde esta idea surge, Paisaje de lo inesperado, una configuración del concepto lugar a partir de mi experiencia vital. Lo virtual aparece como representación del concepto lugar a través de la idea de deriva, generando otras posibilidades a partir de nuestras subjetividades, tejiendo un espacio de conexiones e intuiciones para hacer visible aquello que no está representado. Experiencias o emociones que favoreciendo la aparición de lo inesperado como parte del proceso creativo, otras narrativas que desarrollo como investigación y metodología de enseñanza en contextos educativos.
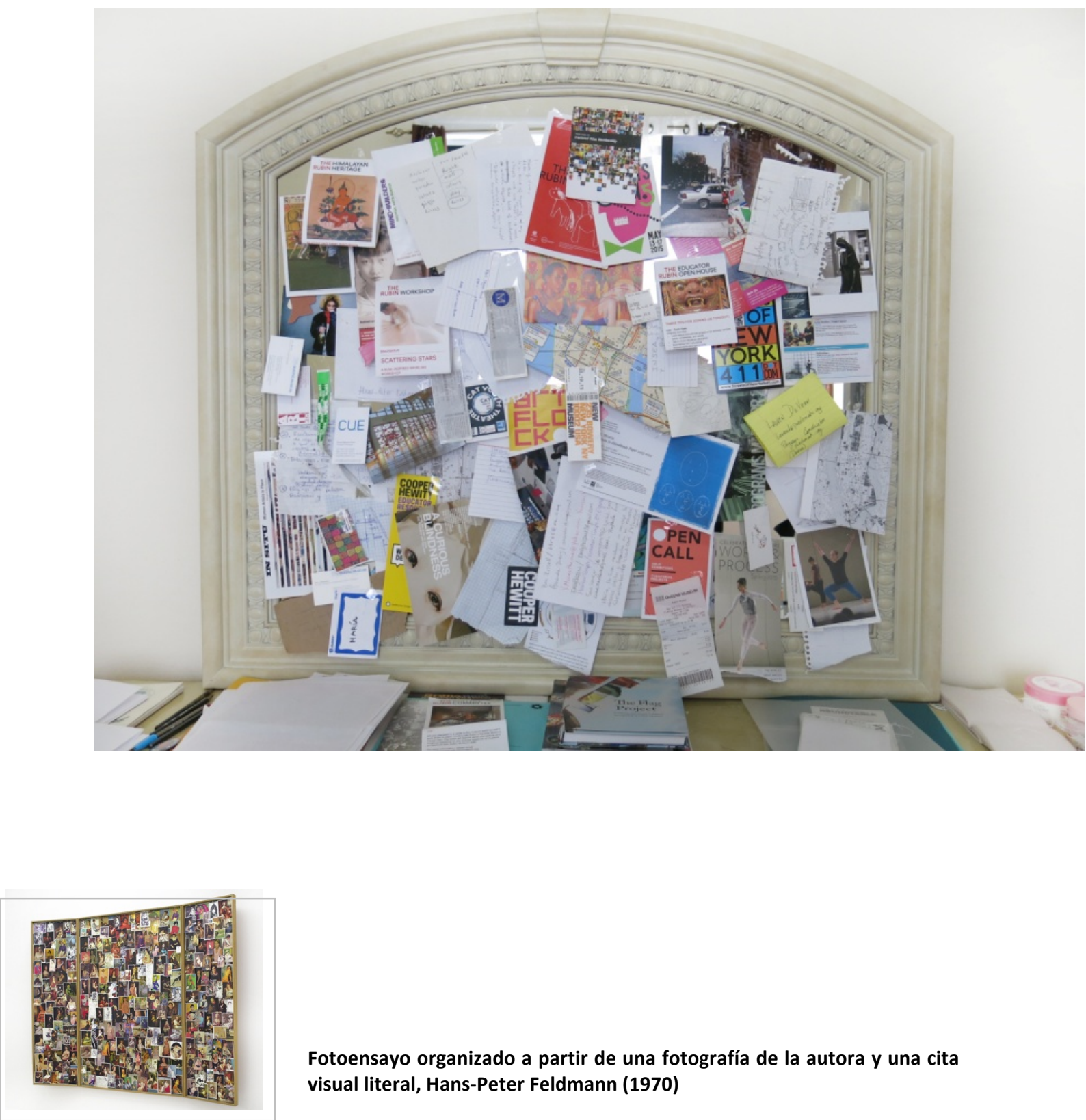

Fotoensayo organizado a partir de una fotografía de la autora y una cita visual literal, Hans-Peter Feldmann (1970)

La acción se articula en torno a una serie de conversaciones que comparto de forma fortuita durante cada uno de los paseos por las calles del barrio, durante un café en el bar de enfrente o en el metro al preguntar por el número de una parada, conversaciones que van guiando mi recorrido, descripciones, mapas, nombres... lugares que voy descubriendo a través de las palabras que intercambio con los paseantes que encuentro en el camino, instantes que van creando un inventario de memoria colectiva del espacio urbano, generando una gran posibilidad de formas de habitarlo. 
Cada recorrido comienza a partir de una conversación con un vecino del barrio, una peluquería, o el laundromat, lugar donde trabaja Teresa, una mujer de República Dominicana que describe el barrio como "un pedacito de mi tierra", a ella le gusta pasear por el parque Fort Tryon, allí encontré a Luis, quien me comentó que en el Malecón los cafés son de verdad, de esta forma sigo un camino inesperado en el que voy anotando las mis percepciones del lugar, imagino, fotografío y escribo, creando una tejido de narrativas visuales desde una mirada autoetnográfica.

Hago referencia a obras de varios artistas que trabajan con narrativas de archivo como On Kawara y sus cuadernos-ficheros I Met, I Red, I Went donde una serie de hojas con nombres registran las personas con la que On Kawara se encuentra, las cosas que lee o los lugares que visita cada día. Una forma de representación de espacio-tiempo continua y acompañada a los pasos de su día a día. Desde el concepto de memoria como acumulación, escojo la obra de Walter Benjamin, Pasajes, donde va alternando documentos autobiográficos con conjuntos de «citas» sobre fuentes ya publicadas, de esta manera, la vida de Benjamin queda configurada a modo de anotaciones, borradores e instantes como fotogramas. Por otro lado me interesa los paneles de Mnemosyne de Warburg, y su discurso al configurar un nuevo orden en la historia a través de nuevas combinaciones que posibilitan otras narrativas. Su obra se articula en torno a un conjunto aleatorio de relaciones artísticas o collage de imágenes y expresiones corporales (imágenes de las culturas no-occidentales, imágenes de arte, artes decorativas, ciencia, periódicos...) donde el concepto de archivo, aparece como dispositivo de almacenamiento de memoria cultural.

Los mapas que presento se aproximan a la idea de álbum de Hans-Peter Feldmann, su obra funciona desde la perspectiva de álbum biográfico en el sentido que se articula en torno a memorias, son narrativas visuales y objetos cotidianos que colecciona. Por otro lado mantengo la idea de obra como proceso, algo inacabado que registra el paso del tiempo, ligado a la vida a como acto cotidiano.

Desde la perspectiva artístico-social estos los mapas se configuran como un dispositivo que me permite "representar la experiencia del espacio vivido a través del cruzamiento de redes espaciales y temporales, tomando las figuras del entramado y de planos sobrepuestos como estructura poética" Amaral, L.( 2013) Los mapas me generan la posibilidad de reflejar redes de conexiones, una composición visual, mezcla de texturas, colores, formas... de culturas cruzadas, un espacio donde se puede ser varias cosas a la vez, la presencia de una amplia diversidad cultural mezcla de gustos de diferente procedencia antes completamente separados, en una especie de "collage" que potencia estas relaciones interculturales, generando la posibilidad de crear mundos imaginados o virtuales. 


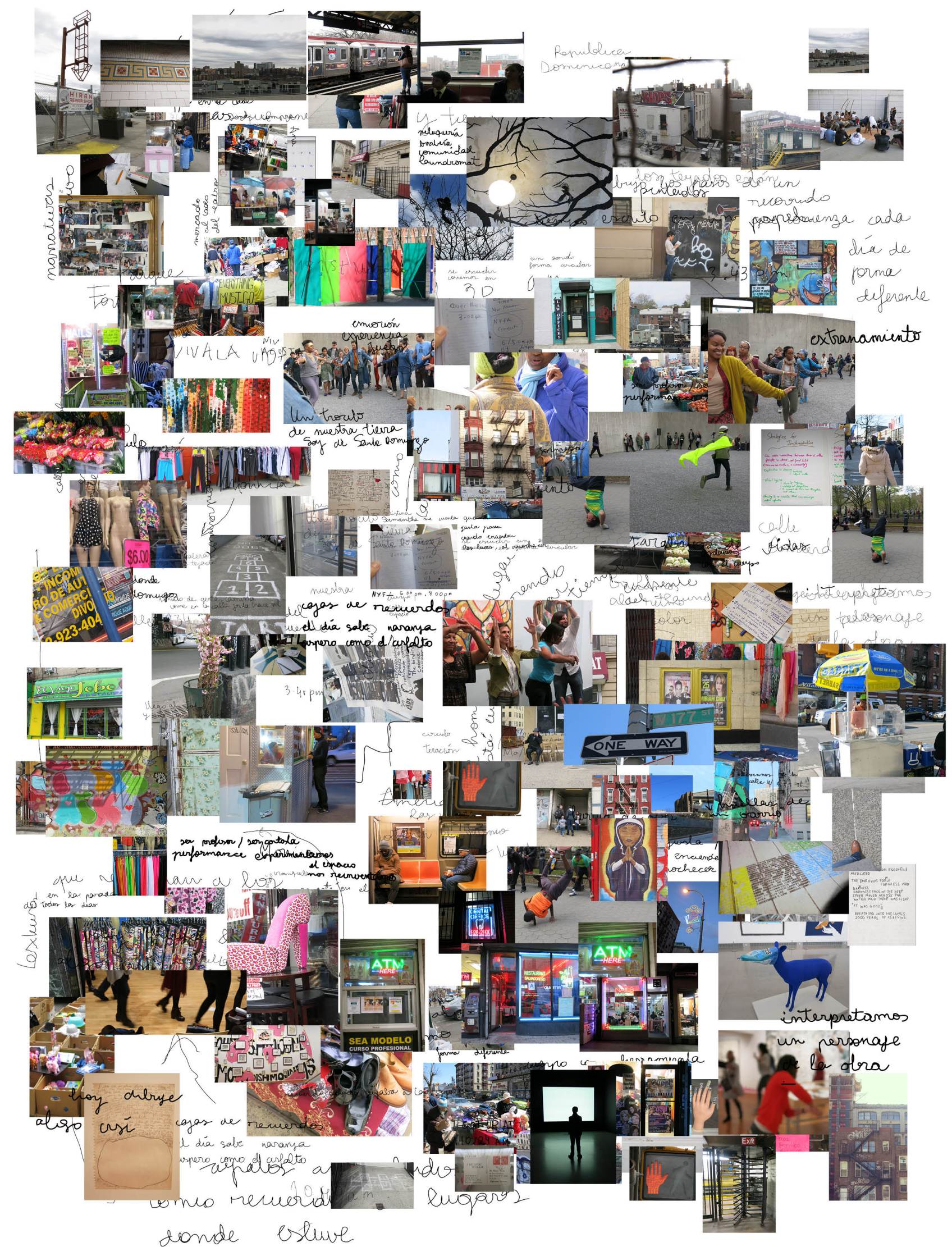




\section{Metáforas de papel}

Una acción como representación virtual de un lugar.

Sigo el camino de la deriva, donde el proceso es un fin en sí mismo y el concepto de psicogeografía enriquece mi creación artística, surgiendo ideas y propuestas que van cambiando según voy caminando o encontrado nuevas situaciones. Según Maria jesús Agras Pardiña, el comportamiento lúdico-constructivo y la subjetividad de las rutas (mirada que construye) que cada quien elige en su deambular por la ciudad reinterpretan nuestra visión urbana y la convierte en un material de reflexión o creación artística. De esta manera surge la acción que presento a continuación, en la puerta de un colegio, al lado de la calle donde vivo.
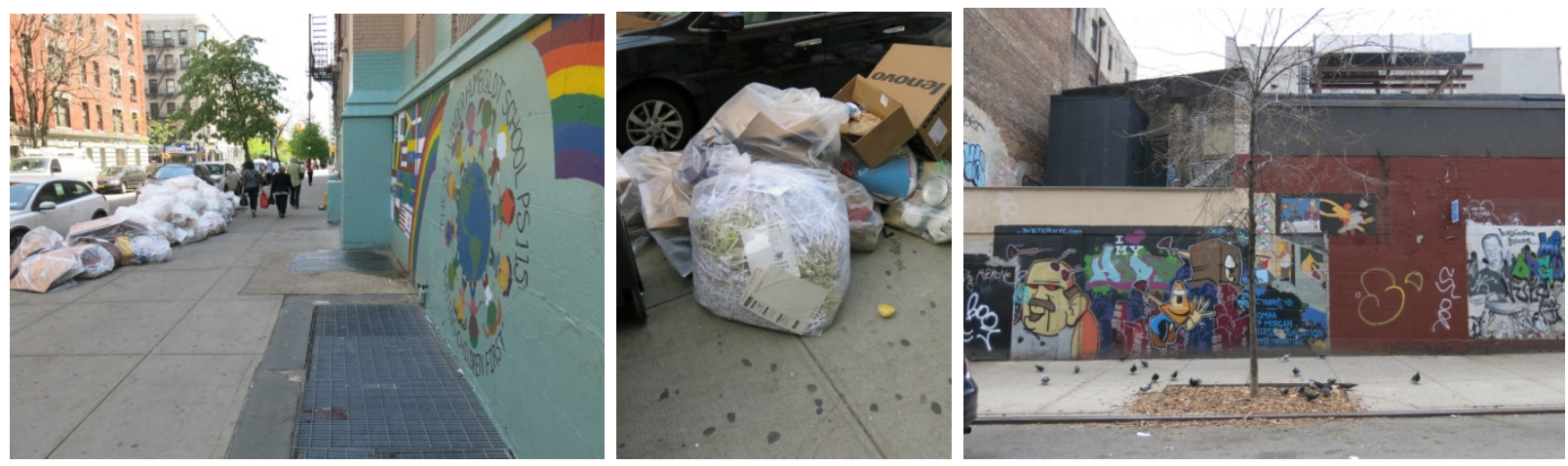

Fotoensayo organizado a partir de tres fotografías de la autora, Sin título 2015 .

La acción se basa en la idea de representación de lugar como acumulación de experiencias. Realizo una acción a partir de bolsas encontradas enfrente del colegio de papel cortado, guías, programaciones, fichas, manuales...etc. todo tipo de material escolar.

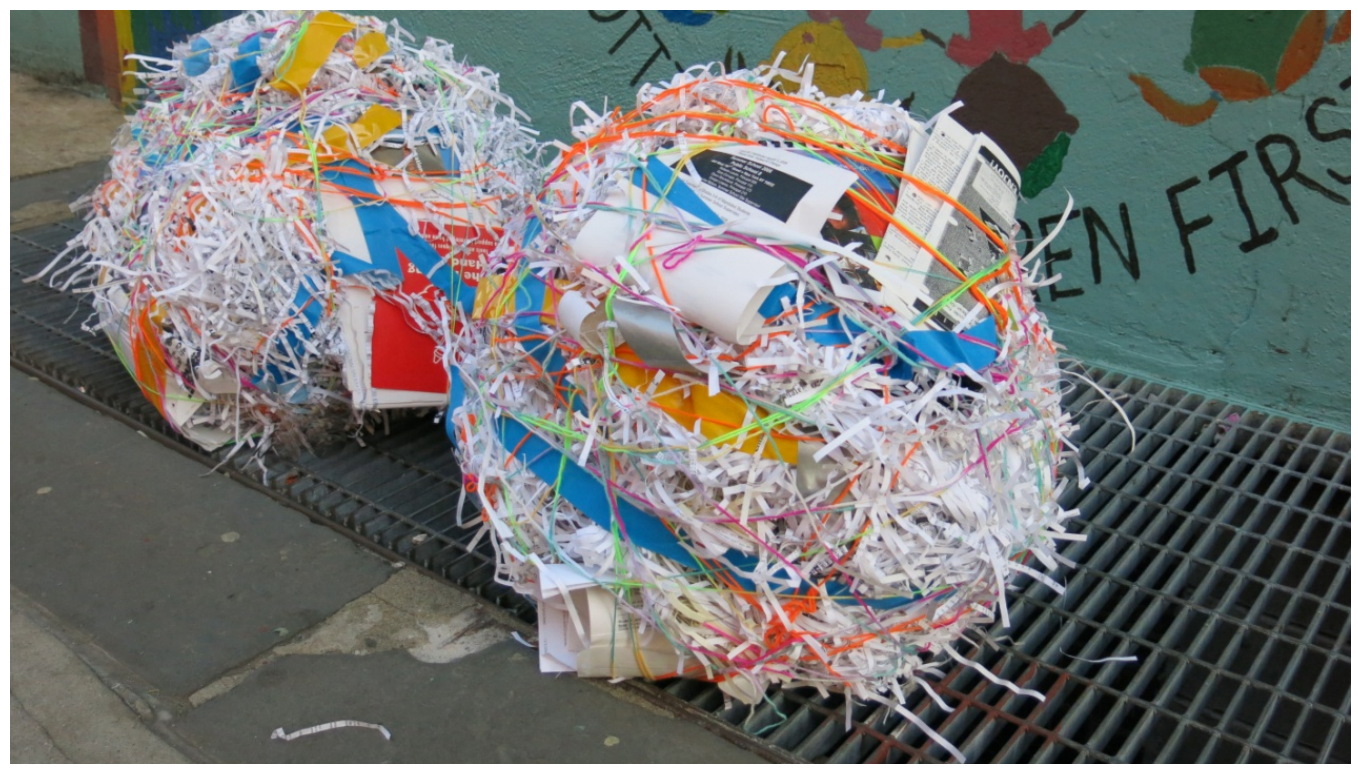

Fotografía independiente de la autora , Sin título 2015. 


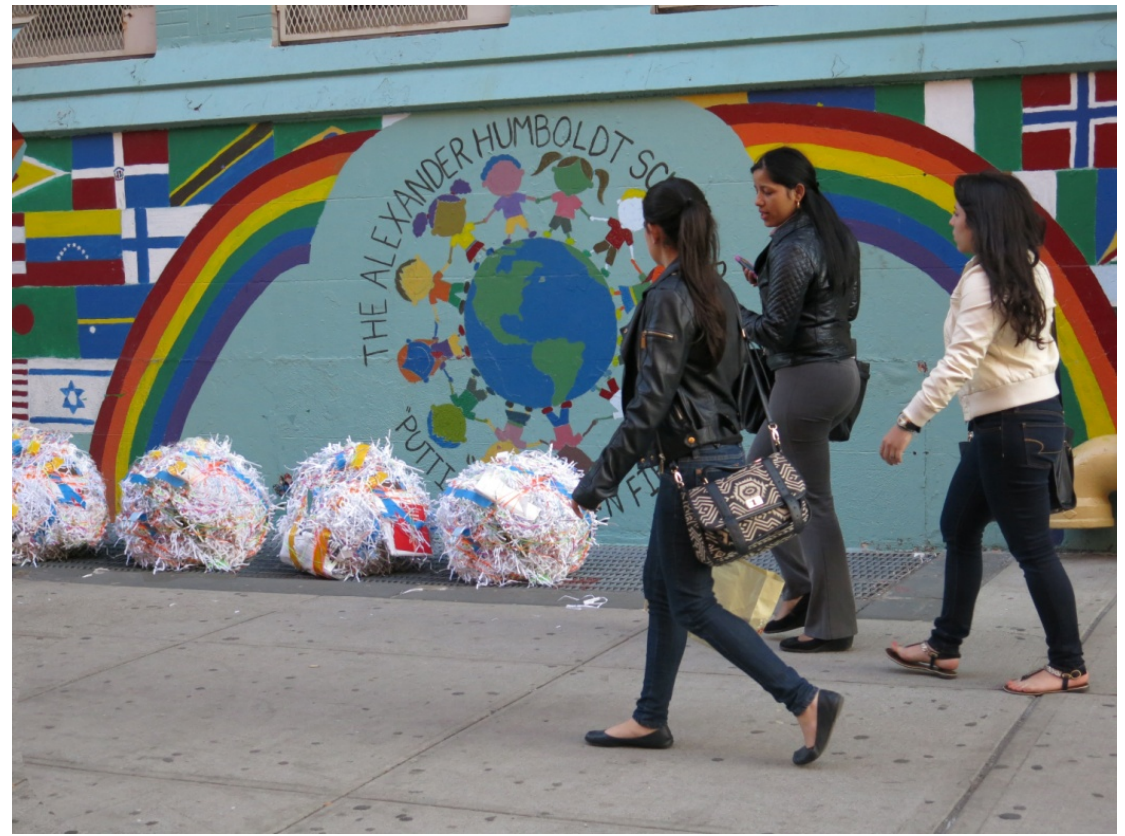

Fotografía independiente de la autora, Sin título, 2015.

\section{Cuaderno de clase.}

Una propuesta educativa basada en la deriva como metodología artística
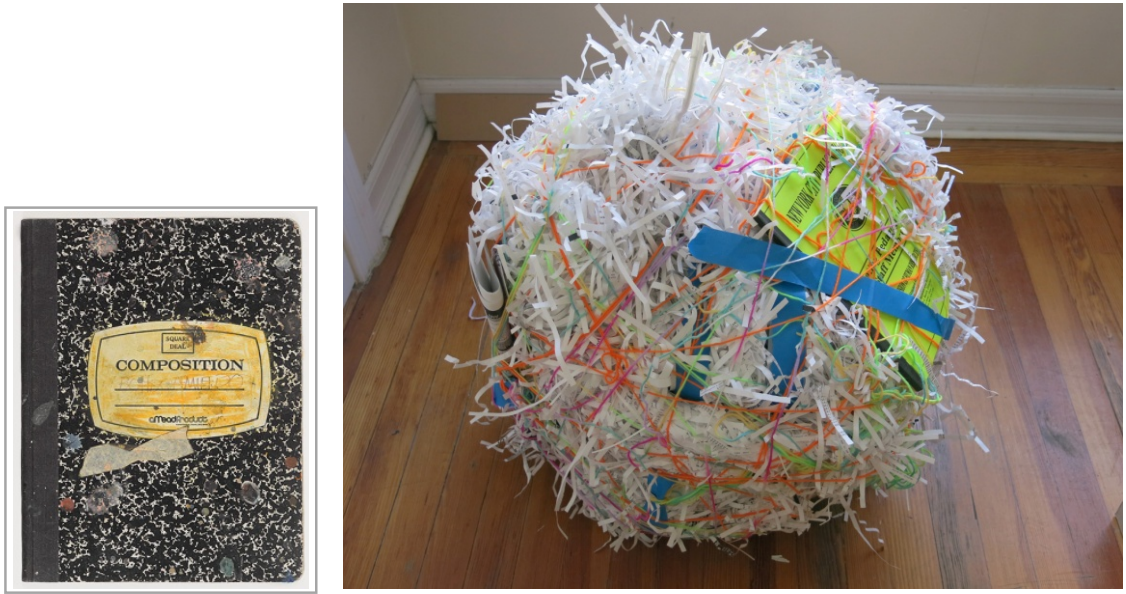

Fotoensayo organizado a partir de una fotografía de la autora y una cita visual, Basquiat (1980).

El arte actual nos permite pensar la realidad desde otro lugar y cuestionar todo aquello que es asumido sin reflexionar. Por ello pienso que resulta urgente la necesidad de incorporar la creación artística a cualquier contexto educativo. Entiendo el arte y la educación como procesos de investigación a partir de mi experiencia vital, procesos de investigación/creación que sirven para comprender el mundo y situarnos en él. Me interesa la de la idea de recorrido como proceso metodológico, una forma de favorecer experiencias que puedan generar aprendizaje. De esta manera, desarrollo una metodología de enseñanza a modo de deriva, como proceso de aprendizaje con el objetivo de visualizar lo que no está representado.

La siguiente propuesta es una acción a partir de una metodología artográfica, Tiene como punto de partida la obra de Jean-Michel Basquiat, cuadernos donde las palabras adquieren un significado diferente para representar su forma de ver el mundo Sus dibujos me recuerdan a mapas de historias vividas a través de la representación de acciones de la vida cotidiana. Crea mundo de grafismos para contar experiencias, un cuaderno inacabado de acciones que representa a través de palabras y dibujos de lo que va aconteciendo en su vida. La acción que presento parte de la idea de cuaderno como metáfora docente a través de los cuadernos de clase de Basquiat. 
La actividad se desarrolla en contexto museístico con un grupo de profesores de diferentes lugares. Una metáfora sobre nuestra actividad docente a través de una acción colectiva. Cada uno de nosotros realiza anotaciones de acciones cotidianas para representar un cuaderno de clase.Un puzzle gráfico creado por las distintas experiencias, sonidos, sabores, etc. que experimentamos día a día. Para ello comenzamos contando algo, escribiendo o dibujando algo lo que habíamos experimentado esa mañana, como un sonido, un pensamiento o una acción cotidiana.
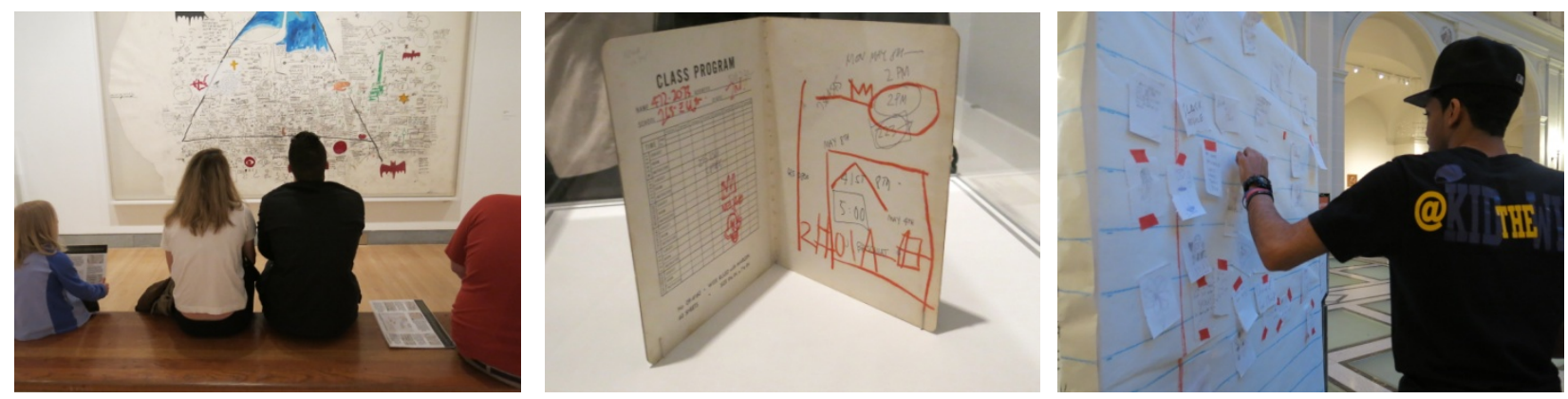

Fotoensayo organizado a partir de dos fotografías de la autora y dos citas visuales indirectas, Basquiat (1986) y Basquiat

Con esta idea propongo la descontextualización del objeto cuaderno de clase y la construcción de un cuaderno basado en el concepto de deriva a partir de la obra de Basquiat, una experiencia colectiva para hacer visible aquello que no está representado, una reflexión sobre nuestra identidad profesional. A partir de esas representaciones gráficas, construimos el cuaderno a través del cuerpo, desde el movimiento, creamos la identidad sonora basada a en sonidos dibujados, interpretamos las palabras desde una acción colectiva introduciendo lo lúdico como parte del proceso de aprendizaje y el cuerpo como centro de percepción.
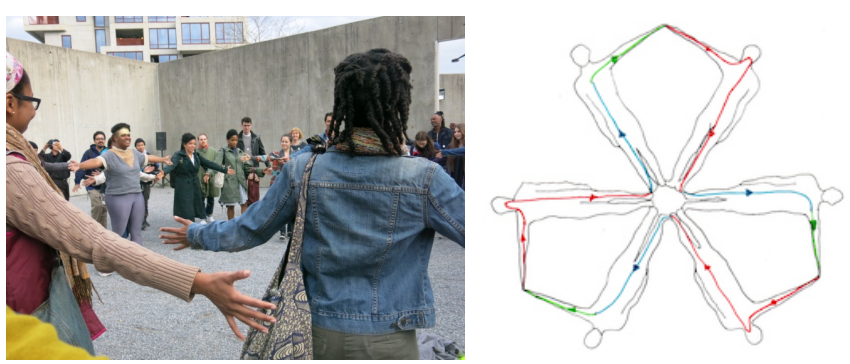
Fotoensayo organizado a partir de una fotografía de la autora y un cita visual Katrien Oosterlinck (2014).

\section{CONCLUSIÓN}

Historia de un barrio parte de la idea de narrativas de archivo, desde la acumulación de imágenes, palabras, papeles de un lugar que a modo de memoria voy guardando. Desde la idea de archivo creo el concepto lugar a través de una deriva de acciones que van generado otras formas de representación. El concepto de lugar como representación virtual cambia a lo largo de la investigación afectado por las experiencias que van sucediendo en el tiempo generando Metáforas de papel. El concepto deriva como representación virtual del lugar, permite la construcción de un paisaje inesperado que tiene en cuenta nuestra subjetividad, favorece otras formas de representación de lo "real", desarrollando una mirada crítica hacia nuestro entorno.

Con esta acción indago la idea de deriva o representación virtual desde una acción compartida como metáfora docente. Me ha permitido generar otras formas de representación y ireflexiónar sobre nuestra identidad profesional en torno a la mirada artistaeducador a través de un mapa de grafismos que conecta distintas experiencias que parte de nuestra memoria como individuo y como colectivo.

Lo virtual como forma de reinventarnos, de imaginar o de crear otras posibilidades de representación. Desde esta perspectiva el cuaderno de clase es reinventado desde la acción colectiva. Durante el proceso compartimos historias, nos identificamos a través de la mirada del otro, experimentamos una constante mutación e interacción entre diferentes culturas, sonidos, historia.... distintas experiencias. Pienso el concepto de deriva nos ha permitido crear un amplio registro de identidades, de reinventamos a través diferentes acciones para crear un lugar como espacio de relaciones, de interacciones con los demás, generando otras formas de habitarlo. 


\section{FUENTES REFERENCIALES}

AGRAS PARDIÑA, Ma JESÚS (2012). Historias en torno al arte y a la educación artística: Notas para un posible diario. http://www.apecv.pt//APECVPublications/Agra.HistoriasdeEd.Artistica.pdf

Amaral, L. (2013) entrevista a Lilian Amaral extraído del texto: http://clio.rediris.es/n40/articulos/mono/MonCabezoMoncada2014.pdf

BOURRIAUD, Nicolás (2006). Estética Relacional, Adriana Hidalgo Ed., Buenos Aires 2006.

DEBORD, G.(1958). Teoría de la deriva. Texto extraído de la publicación :

http://www.ugr.es/ silvia/documentos\%20colgados/IDEA/teoria\%20de\%20la\%20deriva.pdf

DEWEY, J. El arte como experiencia. Fondo de Cultura. Méjico. 1944.

FELIU, J. (2007). Nuevas formas literarias para las ciencias sociales: el caso de la autoetnografía. Athenea Digital. http://psicologiasocial.uab.es/athenea/index.php/atheneaDigital/article/view/447

HERNÁNDEZ (2008). La investigación basada en las artes. Propuestas para repensar la investigación en educación. Siglo XXI, no26. Murcia: Universidad de Murcia.

IRWIN, R. (2000) A/r/tography. Rendering Self Through Arts-Based Living Inquiry. Pacific Educational Press, Vancouver

MORENO MONTORO, MARÍA ISABEL.(2015) “Hablemos de investigación artística desde la perspectiva de las prácticas intermedia en la creación artística" 3 Conference Arts Based Researh of University of Porto. http://3c.nea.fba.up.pt/programa.

Katrien Oosterlinck (2014) http://ooooo.be/ko/index.php?/new/raaklijnen/ns-Peter Feldmann (1970)

http://www.arteinformado.com/magazine/n/hans-peter-feldmann-del-reina-sofia-a-projectesd-2391

Basquiat (1986)https://www.brooklynmuseum.org/exhibitions/basquiat_notebooks/\#!lb_uri EL135.06.php

Basquiat (1980)https://www.brooklynmuseum.org/exhibitions/basquiat_notebooks/\#!lb_uri EL135.01.01.php 